\title{
Hypophysitis and Granulomatous Pituitary Lesions in Systemic Diseases
}

\author{
Marie-Lise Jaffrain-Rea and Silvia Filipponi
}

\section{Contents}

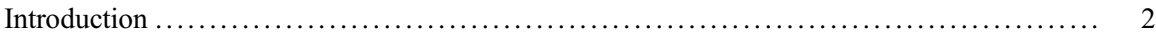

Part I: Autoimmune Lymphocytic Hypophysitis (LYH) in Systemic Diseases ............. 3

LYH in Autoimmune Polyendocrine Syndromes (APS) ........................ 4

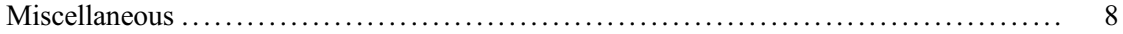

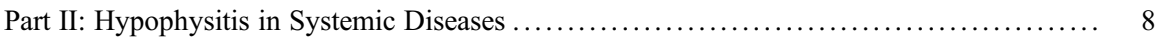

Granulomatous Hypophysitis .......................................... 8

Langerhans Cell Histiocytosis (LCH) and Other Histiocytic Diseases ................ 9

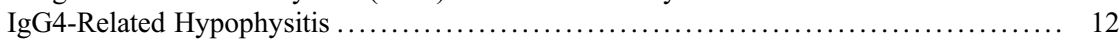

Part III: The Pituitary Gland in Cancer Patients and Immunotherapy-Related Hypophysitis . . 14

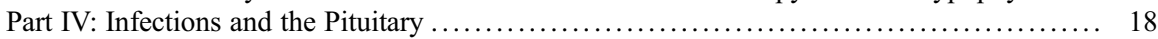

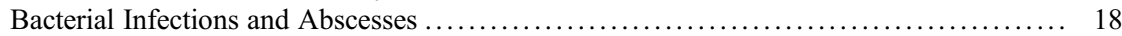

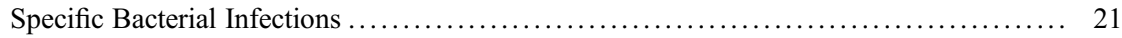

Viral Infections . . . . . . . . . . . . .

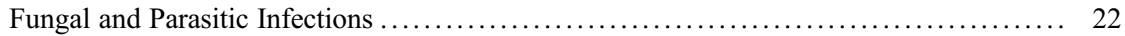

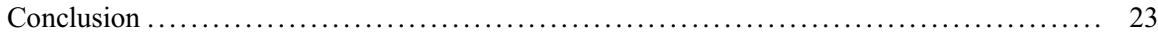

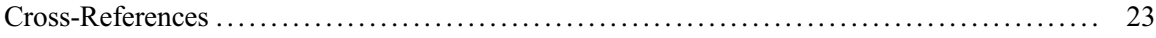

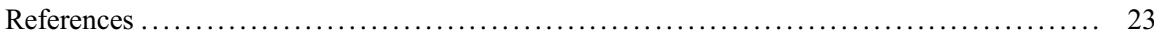

M.-L. Jaffrain-Rea ( $\triangle)$

Department of Biotechnological and Applied Clinical Sciences, University of L'Aquila, L'Aquila (AQ), Italy

Neuroendocrinology, Neuromed, IRCCS, Pozzilli (IS), Italy

e-mail: marielise.jaffrain@univaq.it

S. Filipponi

Department of Biotechnological and Applied Clinical Sciences, University of L'Aquila, L'Aquila (AQ), Italy

A. Colao et al. (eds.), Polyendocrine Disorders and Endocrine Neoplastic Syndromes, Endocrinology, https://doi.org/10.1007/978-3-319-73082-0_6-1 


\section{Abstract}

In clinical practice, expansive sellar lesions are largely represented by primary diseases of the pituitary gland, mostly pituitary tumors, which can be managed by endocrinologists and/or multidisciplinary pituitary teams. Hypophysitis has long been considered as a rare disease, and is classified on the basis of pathological findings, and as primary or secondary. Nowadays, an enlarging spectrum of pituitary and/or hypothalamic inflammatory, granulomatous, or even neoplastic disorders can be recognized, which may be part of systemic conditions and require appropriate multidisciplinary management involving a variety of specialists. For example, hypophysitis is being increasingly recognized in the setting of systemic IgG4-related disorders or as side effects of immune checkpoints inhibitors in oncological patients. Lymphocytic hypophysitis may sometimes be part of autoimmune polyendocrine syndromes. Significant knowledge has been added in the last decade in the pathogenesis and management of histiocytic disorders, which may infiltrate the pituitary and/or the hypothalamus Infective causes of pituitary inflammation should not be underestimated and are increasingly recognized in immunocompromised patients. Based on updated literature on these topics, this chapter aims to place pituitary inflammatory, granulomatous, and histiocytic disorders in their systemic context and stimulate multidisciplinary collaboration in order to optimize their diagnosis and clinical management.

\section{Keywords}

Hypophysitis · Lymphocytic hypophysitis · Granulomatous hypophysitis · IgG4related · Immune checkpoint inhibitors · Histiocytosis · Neurosarcoidosis ·

Tuberculosis

\section{Introduction}

The pituitary gland is a target for a number of localized or systemic inflammatory conditions, which are relatively rare but quite heterogeneous in origin and clinical presentation. Hypophysitis was reported to represent less than $1 \%$ of pituitary masses (Lee et al. 2017), which is likely to be underestimated since data were based on histological reports of primary hypophysitis and an increasing number of cases is no longer treated by surgery. In addition, at a late stage of inflammation, the pituitary gland may recover a normal size or undergo a progressive atrophy, potentially leading to a condition of "empty sella." At onset, pituitary inflammation is typically associated with an increase in pituitary size with frequent mass effects (in particular headache, with potential visual field abnormalities), and pituitary dysfunction, which include diabetes insipidus (DI) where the neurohypophysis/infundibulum is involved, hypopituitarism, and abnormal prolactin (PRL) secretion. Noteworthy, progressive impairment of anterior pituitary functions may occur in a different order as compared to other pituitary masses, and secondary adrenal insufficiency may appear first, potentially leading to life-threatening complications such 
as acute adrenal crisis. Isolated localization to the infundibulum may present as "hypothalamitis" (Bianchi et al. 2014), and hypothalamic-pituitary (HP) involvement is frequent in systemic conditions. Importantly, symptoms of ACTH and TSH deficiency are not specific and usually present as unexplained fatigue or pain, decreased appetite, weight loss, or hyponatremia, which may be underestimated in the setting of a systemic or oncological disease. The clinical picture of hypophysitis is therefore quite heterogeneous, and patients may first present to a variety of specialists, who should be able to suspect this condition. Then, a multidisciplinary team is generally needed to optimize the diagnosis and clinical management. In fact, if the gold standard diagnosis of hypophysitis still relies on pathological examination, surgery may be dispensable in particular settings, whereas appropriate replacement of pituitary deficits is mandatory to avoid acute endocrine complications and improve patient's quality of life (for review see Guaraldi et al. 2018).

Hypophysitis is classified on a pathological basis and may present either as a primary or secondary disease (Caturegli et al. 2005; Carpinteri et al. 2009; Guaraldi et al. 2018). The most common and best characterized form of hypophysitis is primary autoimmune (AI) lymphocytic hypophysitis (LYH), which may be isolated or part of some autoimmune polyendocrine syndrome (APS) (Caturegli et al. 2005; Guaraldi et al. 2017). Primary and secondary granulomatous hypophysitis ( $\mathrm{Gr}-\mathrm{H})$ represent the second most common histological form of hypophysitis. Similarly, Gr$\mathrm{H}$ may be localized to the HP region or be part of systemic conditions. These may be inflammatory or infectious in origin (Carpinteri et al. 2009; Hunn et al. 2014). Xanthomatous and xanthogranulomatous hypophysitis are rare, and some of them are associated with a preexistent pituitary lesion such as a Rathke's cyst (RCC) (Kleinschmidt-DeMasters et al. 2017). Important emerging entities are represented by hypophysitis induced by cancer immunotherapy targeting immune checkpoints or in the setting of an IgG4-related disease (IgG4-RD). These latter conditions are being increasingly recognized and understood (Shikuma et al. 2017; Byun et al. 2017). Other entities have been recently revised, such as histiocytic disorders, which is important for a correct diagnosis and management of the patients, who may be of pediatric age (Pileri et al. 2017).

The aim of this chapter is to focus on systemic diseases associated with inflammatory HP conditions, providing a practical update on their clinical presentation, diagnosis, and current therapeutic options.

\section{Part I: Autoimmune Lymphocytic Hypophysitis (LYH) in Systemic Diseases}

Primary LYH may involve the anterior pituitary, the neurohypophysis, and/or the infundibulum and account for less than $1 \%$ of all operated pituitary masses (Lee et al. 2017). The AI background and pathogenesis of primary LYH as well as its clinical picture and evolution have been extensively reported elsewhere (Caturegli et al. 2005; Guaraldi et al. 2017). Briefly, LYH mainly affects adults in their fourth to fifth decade and is characterized by a female predominance (sex ratio F/M up to 6:1) with 
a major incidence in pregnancy and within 6 months postpartum. Anterior pituitary dysfunction in LYH commonly involves, in a classical order, the somatotroph, gonadotroph, and finally corticotroph/thyrotroph axes. DI occurs in a minority of adult patients (14-20\%) (Caturegli et al. 2005; Guaraldi et al. 2017). Pediatric cases have also been reported, with no gender predominance, and are characterized by a higher prevalence of DI (85\%) and hypopituitarism, in particular GH deficiency (76\%), but a lower prevalence of visual disturbances (8\%) (Kalra et al. 2011). Of note, in young patients the diagnosis of LYH may precede that of a germinoma, which is accompanied by extensive lymphocytic infiltrates, making appropriate follow-up mandatory (Kalra et al. 2011).

Biological evidence of circulating anti-pituitary antibodies (APA) may support the diagnosis of LYH in the presence of a suggestive context. However, due to methodological and specificity issues, their diagnostic value is not so clear-cut as compared with organ-specific antibodies in other AI endocrinopathies. Several APA have been identified and, despite background issues and the absence of universal standardization, indirect immunofluorescence remains the preferred method for their identification (for review see Guaraldi et al. 2017). In some cases, clinical correlates between APA and hormone deficiencies have been reported, such as GH/TSH/PRL insufficiency in the setting of an anti-Pit syndrome (Bando et al. 2017).

\section{LYH in Autoimmune Polyendocrine Syndromes (APS)}

Out of 376 adults with LYH, 67 (18.0\%) were reported in association with other AI, the most frequent being AI thyroiditis (7.4\%) (Caturegli et al. 2005), with similar observations in pediatric forms (Kalra et al. 2011), thereby raising the suspicion of AI polyendocrine syndromes (APS) or multiple AI syndromes (MAS) - this latter term being proposed because of the remarkable frequency of non-endocrine AI diseases (Betterle and Presotto 2008). Two major forms of APS (APS1 and APS2) have been identified, whereas associations of AI thyroiditis with other endocrine and non-endocrine AI disorders, or any association of two or more organ-specific AI diseases not meeting the criteria for other APS, have been described as APS type 3 and 4, respectively (Betterle and Presotto 2008) (Table 1). LYH is quite rare in the two major forms of APS and may rather be a feature of APS3 and APS4. To the best of our knowledge, LYH is not a feature of other rare AI conditions, such as IPEX or POEMS syndrome.

APS1, also known as AI polyendocrinopathy-candidiasis-ectodermal dystrophy (APECED), is a very rare and well-defined familial syndrome, due to inactivating mutations in the autoimmune regulator AIRE gene in $21 \mathrm{q} 22.3$, typically transmitted as an autosomal recessive trait, with recent reports of mutations having a negative dominant effect. It is more frequent in some populations, such as Iranian Jews, Finns, and Sardinians, and different mutations may have a founding effect and/or impact disease phenotype (Husebye et al. 2018). The first symptoms of APS1 appear in infancy or in early adolescence, with additional diseases developing at any age throughout the adult life. Endocrine diseases are mostly represented by chronic 


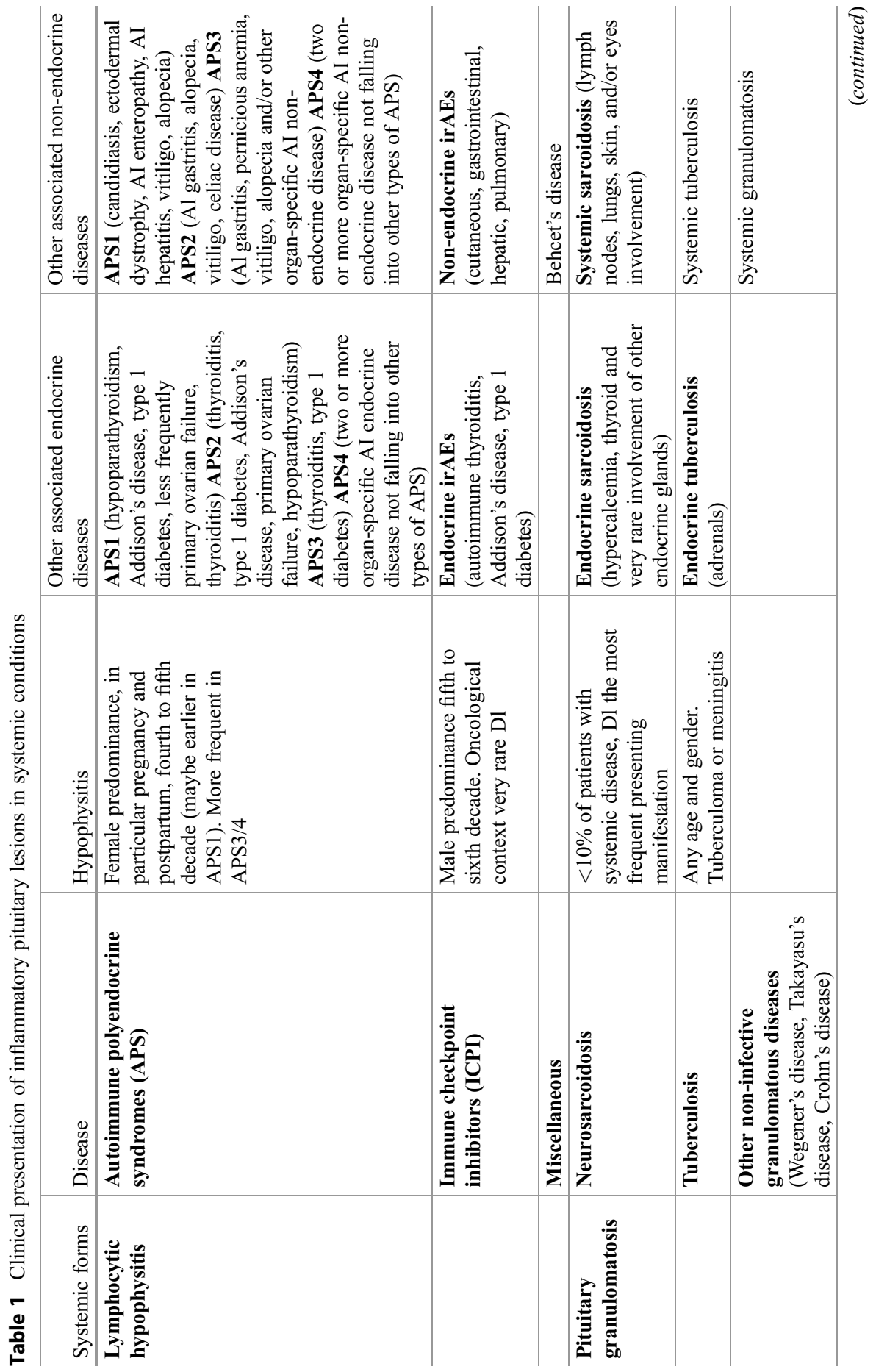




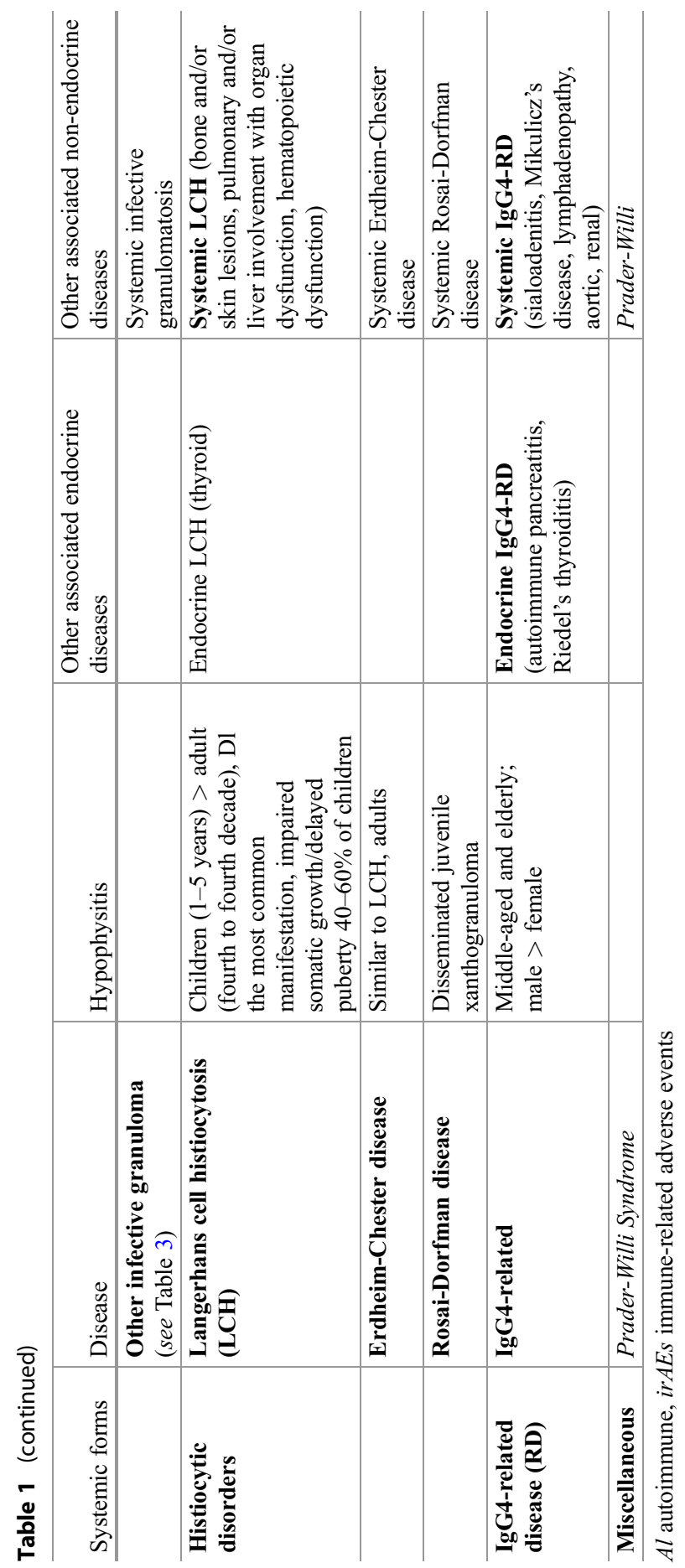


hypoparathyroidism and primary adrenal insufficiency (Addison's disease) (up to $85 \%$ and $70 \%$, respectively), followed by premature ovarian failure, whereas AI thyroiditis and type 1 diabetes mellitus are less frequent (up to 10-20\%) (Husebye et al. 2018; Kahaly 2009). Although APA have been observed in APS1 patients (Bensing et al. 2007), LYH and hypopituitarism, including growth delay due to pediatric GH deficiency, are quite uncommon in APS1 (Kahaly 2009; Bensing et al. 2007).

APS2 is a rather common disorder (estimated prevalence 1:1000), defined by the association of at least two of the three following endocrinopathies: AI thyroiditis, Addison's disease, and type 1 diabetes. It typically develops during adolescence or early adulthood, with a complex multigenic hereditability and a strong association with some HLA haplotypes. Of note, the gene encoding CTLA-4, which is involved in the development of hypophysitis induced by CLT4-A antibodies in cancer patients (see further on), is among the predisposing genes to APS2 (Husebye et al. 2018). However, no more than $2 \%$ of APS2 patients appear to develop LYH (Kahaly 2009).

The prevalence of LYH and APA was evaluated in a large survey of patients affected by APS $3 / 4$ by the Italian AI hypophysitis network (Bellastella et al. 2010). Remarkably, despite the debated predictive value of APA, $18 \%$ of a cohort of 149 patients showing evidence of circulating APA developed pituitary dysfunction over a 5-year follow-up period versus none of 50 APA-negative cases. Impairment of a single pituitary function was observed in most cases $(64.3 \%, \mathrm{GH}>$ gonadotropin $>$ ACTH deficiency), but combined pituitary deficiency was also frequent (35.7\%). Potential mass effects or DI were not reported, and no data concerning neuroradiological imaging was provided (Bellastella et al. 2010).

AI endocrinopathies and gastritis have also been recently associated with the "anti-Pit1 syndrome" which therefore enter the spectrum of APS. Importantly, this rare syndrome was recently associated with the presence of a thymoma, ectopic expression of Pit1 in the thymus may be causative, and thymectomy has proven to reduce the concentrations of anti-Pit-1 antibodies (Bando et al. 2017).

No particular recommendation has been made concerning the treatment of LYH in the setting of APS. Therefore, the approach may range, as for isolated primary $\mathrm{LYH}$, from a wait-and-see option to active treatment with high-dose glucocorticoids (GC) or surgery for the most symptomatic cases, with the occasional use of other immunosuppressive treatments or radiotherapy. As no consensus guidelines or GC protocols are available yet, the decision should be made on the basis of data obtained in primary hypophysitis and multidisciplinary evaluation of single cases (for review see Guaraldi et al. 2018). Briefly, surgery should be considered where the differential diagnosis with other nonfunctioning lesions of the pituitary is unclear and/or in the presence of mass effects, keeping in mind that pituitary function may worsen (Honegger et al. 2015). Although the rate of improvement of pituitary function and DI on GC treatment has been variably estimated in the literature (Honegger et al. 2015; Lupi et al. 2011), the efficacy of GC on headache and a greater chance to improve endocrine dysfunction explain the current trend to favor a medical approach in most cases (Kyriacou et al. 2017). However, long-term hypopituitarism and/or DI, as well as recurrences, may occur with either approach, justifying the need for long- 
term follow-up and appropriate long-term replacement therapies. The presence of additional diseases in APS patients should also be considered.

\section{Miscellaneous}

Hypophysitis with pituitary enlargement and partial hypopituitarism responding to CG and cyclophosphamide has been occasionally reported in the context of Behcet's disease, presumably on an AI basis (Tao et al. 2018). Autoimmunity has also been recently suggested to play a role in the frequent impairment of pituitary function observed in Prader-Willi patients, especially in those due to maternal uniparental disomy for chromosome 5 (Grugni et al. 2018). However, no clinical picture of LYH, such as mass effects or DI, was reported in these patients.

\section{Part II: Hypophysitis in Systemic Diseases}

HP localizations of systemic granulomatous, histiocytic, and IgG-4 related diseases (Ig4R-D) may develop at any time of disease evolution and in some cases reveal the disease. This should be kept in mind in order to make a proper diagnosis and appropriately plan the replacement of hormone deficiencies and the work-up and treatment of the underlying systemic condition.

\section{Granulomatous Hypophysitis}

Gr-H is the second form of primary hypophysitis in pathological series (Hunn et al. 2014). Of note, Gr-H may occur as a complication of a preexisting pituitary lesion, in particular a ruptured RCC, or be secondary to an infectious or noninfectious granulomatosis, and therefore be part of a potentially systemic condition.

Among noninfectious granulomatous conditions involving the HP region, neurosarcoidosis is the best characterized, despite its rarity (Martin-Grace et al. 2015). Clinical manifestations of neurosarcoidosis occur in less than $10 \%$ of patients with systemic sarcoidosis and are exceptionally isolated. In up to $25 \%$ of the cases, HP dysfunction develops as a consequence of a hypothalamic - less frequently pituitary - infiltration by the granulomatous process. The most frequent symptoms are DI $(>35 \%)$ and secondary amenorrhea (nearly $60 \%$ in females) due to hypogonadotropic hypogonadism $(30 \%)$ and/or hyperprolactinemia $(17 \%)$, while hypothalamic manifestations are less common (Martin-Grace et al. 2015). The most frequent manifestations of systemic sarcoidosis are summarized in Table 1, including endocrine complications dominated by hypercalcemia (Porter et al. 2003). Gr-H has been occasionally reported in other systemic conditions such as granulomatosis with polyangiitis (Wegener's granulomatosis), Takayasu's disease, and even Crohn's disease (Carpinteri et al. 2009). Granulomatous infections will be described subsequently. 


\section{Langerhans Cell Histiocytosis (LCH) and Other Histiocytic Diseases}

According to the last classification by the World Health Organization (WHO), "histiocytic neoplasms are derived from mononuclear phagocytes (macrophage and dendritic cells) or histiocytes" and include Langerhans cell histiocytosis $(\mathrm{LCH})$ and very rare entities such as Erdheim-Chester and Rosai-Dorfman diseases (Pileri et al. 2017). Potential HP involvement has been reported in all cases but has been best characterized in $\mathrm{LCH}$, in which DI does not infrequently reveal the disease.

The most frequent manifestations of $\mathrm{LCH}$ are summarized in Table 1. The diagnosis of LCH should possibly include at least a pathological proof of the disease (Girschikofsky et al. 2013). A neoplastic proliferation of Langerhans-type cells is observed, showing immuno-positivity for CD1a, langerin, S100 protein, and Birbeck granules by ultrastructural examination (Weiss et al. 2017). Following a long debate about the inflammatory versus neoplastic origin, $\mathrm{LCH}$ was finally recognized as a neoplastic proliferation of myeloid dendritic cells characterized by an overactivation of the MAPK pathway, which in turn may be driven by somatic mutations such as $B R A F^{V 600 E}$ (>50\%), MAP2K1 (up to 20\%), and MAP3K $(10 \%)$ (Allen et al. 2018; Zinn et al. 2016). Progresses in the understanding of the disease are translating into significant changes in the therapeutic approach to $\mathrm{LCH}$, including target therapies.

From a clinical point of view, $\mathrm{LCH}$ is more frequent in children and often develops in early infancy (1-5 years), but the disease may develop at any age, and most adults are in their third or fourth decade at diagnosis. The clinical picture is quite heterogenous, ranging from localized to multifocal or multisystem lesions, severe disseminated forms being prevalently reported in children (Donadieu et al. 2004a; Girschikofsky et al. 2013). Lung, liver, spleen, and bone marrow localizations and hematological dysfunction are considered as the most severe (Monsereenusorm and Rodriguez-Galindo 2015). HP involvement occurs in about $20 \%$ of LCH patients and typically manifests as DI, which is the most common endocrine disorder and may represent the first disease manifestation. Anterior pituitary dysfunction rarely occurs in the absence of DI and typically leads to progressive and permanent hypopituitarism. Impaired somatic growth and delayed puberty may reveal GH and gonadotroph deficiencies in children (40-60\%). Postpubertal hypogonadism may occur as a consequence of hypopituitarism and/or hyperprolactinemia, which is mostly observed in adults. ACTH and TSH deficiencies may subsequently complete the picture of HP dysfunction (Donadieu et al. 2004a; Girschikofsky et al. 2013). Of note, hypothalamic symptoms were also recognized in about half of adult patients affected by HP-LCH, including hyperphagia leading to overweight or morbid obesity, sleeping abnormalities, and less frequently thermoregulation abnormalities and adipsia (Kaltsas et al. 2000). MRI may show a disappearance of the normal posterior pituitary, an isolated thickening of the stalk or sellar/suprasellar masses (Fahrner et al. 2012; Girschikofsky et al. 2013) (Fig. 1). Neuroradiological follow-up of LCH patients may reveal progressive neurodegenerative (ND) changes involving the cerebellum and the basal ganglia and/or the pons, ranging from mild to severe alterations and potentially leading to a 


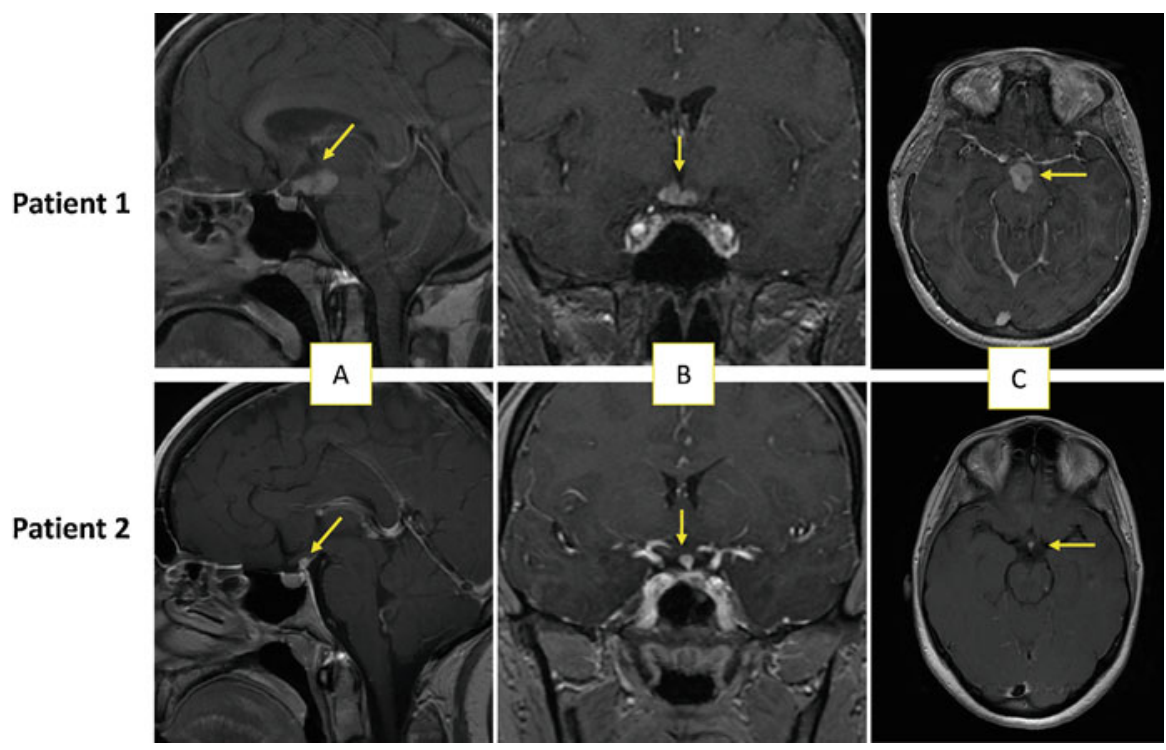

Fig. 1 MRI in pituitary-hypothalamic Langerhans cell histiocytosis (LCH). Shown are gadolinium-enhanced sagittal (a), coronal (b), and axial (c) T1 views of the hypothalamic-pituitary region on brain MRI in two young female patients with LCH. LCH lesions are indicated by a yellow arrow. Patient 1: large hypothalamic LCH involvement in a 21-year-old patient, with diabetes insipidus, secondary amenorrhea, hypopituitarism, and hypothalamic syndrome (severe progressive polyphagic obesity and sleep disorders). No systemic localization was found, and a pathological diagnosis of LCH was obtained on a neurosurgical biopsy. Patient 2: a pituitary stalk LCH nodule in a 31-year-old patient with diabetes insipidus followed 2 years later by secondary amenorrhea with normal PRL levels. The pathological diagnosis of LCH was made on a bronchoalveolar lavage for pulmonary LCH at the age of 26. (Unpublished personal observations)

variety of overt neuropsychological disabilities (Fahrner et al. 2012). More recently, symptomatic ND was systematically searched for in the French cohort of pediatriconset $\mathrm{LCH}$, showing a cumulative risk of $4.1 \%$ at 10 years, with risk factors including HP, skin, and skull base/orbit bone involvement (present in $86.1 \%, 75 \%$, and $63.9 \%$ of the cases, respectively). Remarkably, the 10 -year risk of clinical ND was significantly higher in the presence of a $B R A F^{V 600 E}$ mutation $(33.1 \%$ vs $2.9 \%$, $\mathrm{P}<0.02$ ) (Héritier et al. 2018). Clinical surveillance using neurological scales in patients showing neuroradiological evidence of ND may be useful to recognize progressive impairment and timely start chemotherapy (Zinn et al. 2016). Finally, PET- ${ }^{18}$ FDG imaging can be used to identify lesions more accessible than hypothalamic localizations to obtain a pathological diagnosis and/or evaluate disease extension and during treatment to evaluate changes in the metabolic activity of histiocytic lesions (Martin-Grace et al. 2015).

The therapeutic management of patients with $\mathrm{LCH}$ depends on the extent and severity of the disease, ranging from clinical observation to local or systemic therapies (Zinn et al. 2016). Some authors consider HP involvement as an indication 
to chemotherapy in order to prevent disease progression and worsening of pituitary function (Zinn et al. 2016), although some patients with mass effects or disease progression may also benefit from radiotherapy (Kaltsas et al. 2000). In the presence of a multisystem $\mathrm{LCH}$, the standard of care relies on vinblastine and prednisone, which may cure less than $50 \%$ of patients, but the optimal duration of treatment is still uncertain (from 6 to 12 or even 24 months) (Allen et al. 2018; Zinn et al. 2016). Patients with refractory and/or relapsing LCH have been offered different types of salvage chemotherapy regimens - sometimes with a high toxicity - and allogenic hemopoietic-cell transplantation has been proposed with promising results (Allen et al. 2018; Zinn et al. 2016). Target therapies have also been developed for refractory $\mathrm{LCH}$, based on BRAF inhibition with vemurafenib (specific for $B R A F^{V 600 E}$ ) or acting downstream on the MAPK/MEK pathways (Allen et al. 2018). However, these drugs have systemic toxicities, and most trials have been performed in adults. ND may also be responsive to cytarabine or vemurafenib (Allen et al. 2018). Regardless of the oncological approach, HP-LCH requires optimal endocrine management, possibly by an endocrinologist in a multidisciplinary team. Of note, $\mathrm{GH}$ replacement therapy has been safely used in pediatric LCH patients (Donadieu et al. 2004b).

Erdheim-Chester disease (EDC) is a rare, systemic, non-Langerhans histiocytic disease of the adult, with skeletal, neurological, and cardiovascular localizations reported as the most frequent (up to $90 \%, 50 \%$ and $45 \%$ ) (Campochiaro et al. 2015). Retroperitoneal and orbital infiltration determining exophthalmos are also common (25-30\%) (Campochiaro et al. 2015; Cives et al. 2015). Most patients are diagnosed in their fifth to sixth decade, with a moderate male predominance. DI is a classical early manifestation of the disease, but EDC may also involve the anterior pituitary. According to a detailed endocrine evaluation performed in a large series of EDC patients, the prevalence of DI was 33\%, but hyperprolactinemia (44\%) and hypopituitarism were even more frequent, following the classical order of pituitary function impairment (GH, followed by gonadotropin and TSH/ACTH deficiency) (Courtillot et al. 2016). Of note, radiological evidence of pituitary or stalk infiltration on MRI was present in a minority of cases ( $<15 \%$ each), and testicular infiltration was found on ultrasound in $29 \%$ of male patients, explaining the higher prevalence of hypogonadism in men (Courtillot et al. 2016). The first-line treatment of EDC is interferon- $\alpha$, but high-dose GC and different chemotherapy regimens have also been proposed. Based on increased understanding of EDC pathogenesis, target therapies are being increasingly proposed in the last decade, such as tyrosine kinases inhibitors (TKI) and mAbs including vemurafenib (Allen et al. 2018) or tocilizumab blocking the interleukin-6 receptor (Berti et al. 2017). An attractive feature of this last drug is its usually good tolerance. Overall, EDC is a severe condition with a 5-year survival less than $70 \%$, neurological and cardiac localizations carrying the worst prognosis (Campochiaro et al. 2015; Cives et al. 2015).

Other histiocytic disorders include disseminated juvenile xanthogranuloma (a rare proliferation of xanthomatous histiocytes) and Rosai-Dorfman disease. Pituitary involvement has been exceptionally reported (Rotondo et al. 2010; Ferguson et al. 2015). However, these observations should be kept in mind as the differential 
diagnosis between (xantho)-Gr-H and pituitary localizations of histiocytic disorders may be challenging and significantly impact the management and prognosis of affected patients.

\section{IgG4-Related Hypophysitis}

IgG4-RD is a systemic inflammatory disorder, characterized by an infiltration of IgG4-positive plasma cells in different organs, often organized in pseudotumors, typically associated with elevated circulating IgG4 concentrations, and potentially leading to progressive fibrosis and organ failure. An additional characteristic is the high sensitivity of the disease to GC, at least in its inflammatory phase.

The pathogenesis of IgG4-RD is not fully understood, and the role of IgG4 is still controversial. Elements of autoimmunity have long been observed, with potential autoantigens at pancreatic, biliary, and salivary ducts (Stone et al. 2012) and antibodies targeting corticotroph cells in IgG4-RH (Iwata et al. 2017). CD4-positive cells are abundant at inflammatory sites, and type 2 helper (Th2) cell responses predominate in active lesions. Th2 cytokines may contribute to elevated circulating IgE and/or hypereosinophilia, which are frequently observed in IgG4-RD patients $(40 \%)$, and promote collagen deposition and fibrosis in collaboration with additional cytokines released with other inflammatory cells, including regulatory T cells (Tregs) (Stone et al. 2012). Of note, Tregs activation distinguishes IgG4-RD from classical AI diseases, and TGF $\beta$ appears to play a central role in fibrosis. Clonal expansion of B cells producing IgG4 has also been shown, as well as oligoclonal expansion of plasmablasts, the concentration of which is a more sensitive marker of disease activity than serum IgG4 (Kamisawa et al. 2015).

Elevated serum IgG4 may be a useful marker in IgG4-RD but are neither specific nor sensitive enough for diagnosis. Indeed, false-positive increases may occur in other conditions, and false-negative results may be due either to very high levels missed in IgG4 assays (the "prozone effect," which can be recognized by appropriate sample dilution) or to rapid decline on GC treatment, so that up to $30 \%$ of IgG4-RD patients may have normal serum IgG4 (Stone et al. 2012; Kamisawa et al. 2015; Khosroshahi et al. 2015). However, the evaluation of circulating plasmablasts is not widely available, and a number of studies are currently searching for new biomarkers of disease activity and fibrosis in affected patients.

The most frequent manifestations of IgG4-RD are salivary and lacrimal glands swelling (sialoadenitis, Mikulicz's disease), lymphadenopathy, AI pancreatitis, and retroperitoneal fibrosis, but other organs may have been involved, including the thyroid (Riedel's thyroiditis) (Stone et al. 2012; Kamisawa et al. 2015) (Table 1). IgG4-RD lesions may develop synchronously or, more frequently, metachronously. Some of them may mimic malignancy or be life-threatening (pancreatitis, aortic dissection, etc.). IgG4-RD classically affects middle-aged and elderly men, and in a recent systematic review of 3034 patients from different geographical areas, $65-70 \%$ was male, with a mean age at diagnosis ranging from 56.9 to 62 years (Brito-Zeron et al. 2016). However, young onset may occur (Karim et al. 2016). 
IgG4-related hypophysitis (IgG4-RH) entered the spectrum of IgG4-RD in the last 15 years, and a hundred cases were reported until 2015, a majority coming from Japan (Shikuma et al. 2017). However, the prevalence of IgG4-RH among patients affected by IgG4-RD has not been extensively studied yet. In a single-center series of 262 IgG4-RD patients, only 10 (3.8\%) had a documented IgG4-RH (Liu et al. 2018). This prevalence may well be underestimated due to the relatively recent identification of pituitary localizations and should be confirmed in prospective studies. IgG4$\mathrm{RH}$ may be isolated (probably $<10 \%$ ) or present as the first disease manifestation, but it is usually part of a systemic IgG4-RD, and a mean of 3 additional localizations was reported at diagnosis (Shikuma et al. 2017; Liu et al. 2018). IgG4-RH has a modest male predominance (M/F ratio 2.4:1 to 4:1), but the diagnosis may be done early, with a less disseminated disease, in women (Shikuma et al. 2017; Liu et al. 2018). Overall, endocrine deficiencies have been reported in $80-90 \%$ of IgG4-RH patients. DI is the most frequent (up to $80 \%$ ), but some degree of hypopituitarism was reported in more than $50 \%$ of the patients $(\mathrm{FSH} / \mathrm{LH}$ followed by ACTH and TSH insufficiency) (Shikuma et al. 2017; Liu et al. 2018). The prevalence of headache is not well described but appears to be rather low, as well as visual defects, so that endocrine symptoms usually predominate over mass effects. Noteworthy, neurological symptoms may also be caused by additional intracranial localizations, such as pachymeningitis (Kamisawa et al. 2015). At MRI, enlargement of both the pituitary and stalk is the most common finding ( $>60 \%$ ) (Shikuma et al. 2017).

The gold standard diagnosis of IgG4-RD is based on pathological examination, which typically shows a dense lymphoplasmacytic infiltrate with a high proportion of IgG4-reactive plasma cells, storiform fibrosis, and occasional obliterative phlebitis (Stone et al. 2012; Kamisawa et al. 2015). Pathologists should be aware of organspecific variations and differential diagnosis in the presence of IgG4-positive cells (Weindorf and Frederiksen 2017). Interestingly, using as a diagnostic criteria, the presence of a dense lymphoplasmacytic infiltrate with more than 10 IgG4-positive cells per high-power field (HPF) and a ratio of $\mathrm{IgG} 4 / \mathrm{IgG}$-positive cells exceeding $40 \%$, IgGR4-RH was retrospectively found to account for a up to $41 \%$ of primary hypophysitis previously diagnosed as LYH (Bernreuther et al. 2017). Storiform fibrosis was found to be inconsistent and not specific, whereas no obliterative phlebitis was observed, suggesting that these are distinct features of IgG4-RH (Bernreuther et al. 2017). However, pathological examination of the pituitary may be dispensable for the diagnosis of IgG4-RH if sufficient additional elements are present. Leporati et al. proposed that, if the mononuclear infiltration of the pituitary with at least $10 \mathrm{IgG} 4$-positive cells per HPF is sufficient to establish the diagnosis of IgG4-RH (criterion 1), neuroradiological evidence of a pituitary mass and/or stalk enlargement (criterion 2) is also acceptable if associated with any histological proof of IgG4-RD at another site (criterion 3) or with high circulating IgG4 (>140 mg/dl) and a shrinkage of the pituitary mass with symptom improvement on CG therapy (criteria 4 and 5) (Leporati et al. 2011). These criteria have increased the rate of IgG4-RH identification in clinical practice. Of note, early determination of serum IgG4 is strongly recommended owing to their rapid decline on treatment. 
International consensus guidelines for the treatment of IgG4-RD are now available (Khosroshahi et al. 2015). The first-line treatment is represented by GC, and most patients can be initially managed with prednisone at a dosage of $30-40 \mathrm{mg} /$ day and subsequent tapering after a 2-4 weeks period. Due to the high risk of disease relapse, the duration and tapering regimen are still controversial, but slow discontinuation over a 3-6-month period of treatment is proposed by many experts. Based on the natural course of the disease - progressive fibrosis and organ failure - active treatment is indicated at diagnosis in most cases and should be started urgently in the presence of high-risk manifestations (e.g., pachymeningitis, aortic inflammatory aneurysms, involvement of vital organs, etc.), and maintenance therapy may be usefully considered in some patients (Khosroshahi et al. 2015). Noteworthy, IgG4$\mathrm{RH}$ was not discussed in the international guidelines. In a review of 71 cases who received GC (including replacement doses reported in 20 cases), a reduction in pituitary size was observed in all but 2 patients, but no mention is made of pituitary function (Shikuma et al. 2017). Additional options in IgG4-RD are represented by steroid-sparing immunosuppressive therapies (in alternative to GC if contraindicated or in association with GC) or B cell depletion with rituximab (RTX). Of note, surgery may also have a place in the treatment of IgG4-RD, especially in highly fibrotic forms.

\section{Part III: The Pituitary Gland in Cancer Patients and Immunotherapy-Related Hypophysitis}

Potential impairment of HP function in cancer patients has long been recognized, in particular delayed progressive hypopituitarism in patients who received radiotherapy for tumors of the sellar or nasopharyngeal regions or cranial irradiation for hematological malignancies. Such effects are of special importance in survivors from cancers treated in young or even pediatric patients (Crowne et al. 2015) but should also be properly recognized in adult patients. In this setting, the pituitary gland may be either normal in size or reduced in height with a variable degree of intrasellar arachnoidocele ("empty sella"), and DI is exceptional. On the opposite, the development of an evolutive pituitary mass in oncological patients should raise the suspicion of metastasis, which may variably associate symptoms of tumor mass (headache, visual field defects), cavernous sinus invasion (oculomotor nerve palsies with diplopia, palpebral ptosis), and infiltration of the pituitary with impaired endocrine function (hypopituitarism and DI, which is suggestive in this context). Metastasis may complicate the evolution of solid cancers (in particular breast and lung cancer), occasionally lymphomas, and the diagnosis may be tricky in the absence of a previously known malignancy (Castle-Kirszbaum et al. 2018). Alternatively, pituitary infections may be favored by immunosuppression, although this occurs unfrequently in clinical practice. Impairment of pituitary functions and its clinical implications are probably underestimated in cancer patients, including inhibition of the hypothalamic-pituitary-adrenal (HPA) axis by exogenous glucocorticoids. The latter condition may be transient but may significantly impact the quality 
of life and expose patients to acute adrenal insufficiency, which is potentially lifethreatening. In addition, new target therapies such as monoclonal antibodies (mAbs) against growth factor receptors and tyrosine kinase inhibitors may selectively impact some pituitary function (Zatelli et al. 2014), although this has not been systematically analyzed. In the last decade, the development of immune checkpoint inhibitors (ICPI) has induced a new, not unfrequent, entity, represented by AI hypophysitis, thereby enlarging the spectrum of pituitary dysfunction and abnormalities in cancer patients (Fig. 2). Finally, primary pituitary tumors are frequent endocrine tumors, which may be diagnosed incidentally on neuroradiological imaging for oncological purposes (pituitary "incidentaloma"). In contrast with inflammatory or metastatic pituitary lesions, in such cases DI is typically absent at presentation, hypopituitarism is inconstant, and hormone hypersecretion - not limited to moderate functional hyperprolactinemia - may be present (functioning tumors).

ICPI are mAbs designed to target specific molecules involved in immune checkpoints, such as CTLA-4, PD1, and PDL1, aiming to release constraints on immune cells and promote their antitumor activity. Since the first approval of ipilimumab (Ipi) for the treatment of metastatic melanoma in 2011, their indications and use in clinical trials have been progressively extended to additional malignancies, and new

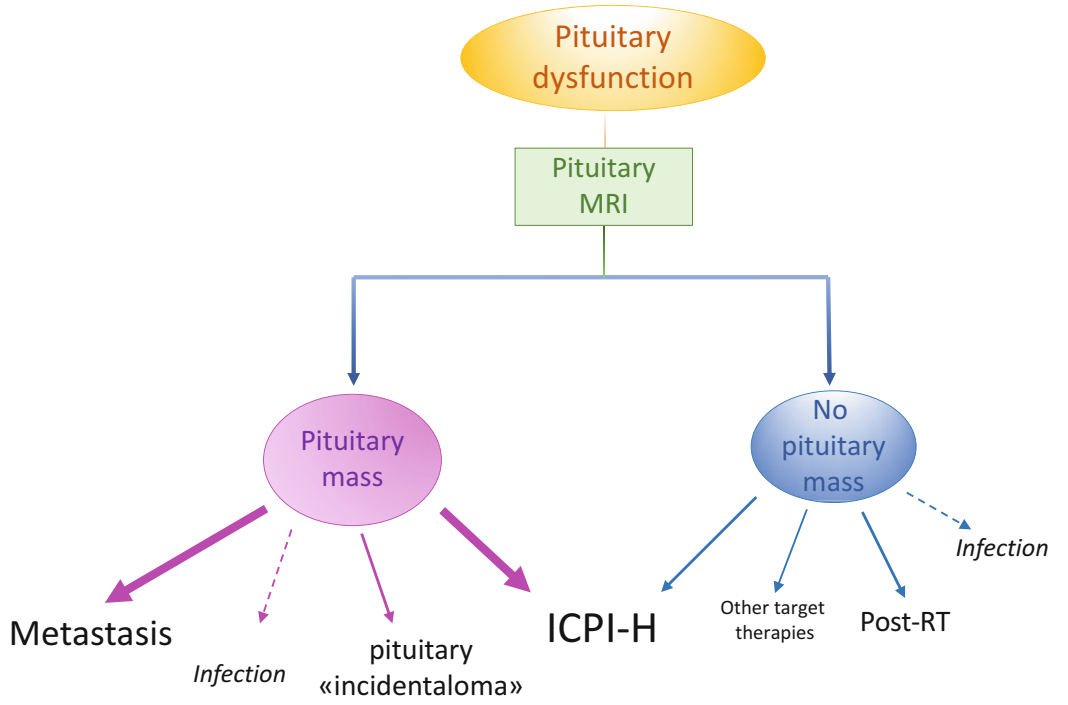

Legend : ICPI-H= Immune Checkpoint Inhibitors Hypophysitis, RT= Radiotherapy

Fig. 2 The pituitary in cancer patients. A schematic approach to the etiology of pituitary dysfunction in oncological patients, according to the presence or the absence of a pituitary mass on MRI. Pituitary dysfunction may include any pituitary deficiency, including multiple hormone deficiency, hyperprolactinemia, and diabetes insipidus - this latter is more suggestive of metastasis or inflammatory disorders, though it is rare in immune checkpoint inhibitor-induced hypophysitis (ICPI-H). Pituitary "incidentaloma" is for any primary lesion of the pituitary, first of all a pituitary tumor. $I C P I-H$ immune checkpoint inhibitors hypophysitis, $R T$ radiotherapy 
mAbs have been introduced (Table 2) (Emens et al. 2017). Because of their mechanism of action, immune-related adverse events (irAEs) involving almost any organ or system are frequent side effects of ICPI. These include endocrine irAEs such as AI thyroiditis and hypophysitis (ICPI-H), rarely primary adrenal insufficiency, or type 1 diabetes mellitus (anti-PD1/PDL1 mAbs only) (Table 2) (Byun et al. 2017). ICPI$\mathrm{H}$ is the most significant endocrine irAE induced by mAbs raised against CTLA-4 and to a lesser extent against PD1 and its ligand PD1L (Faje 2016). CTLA-4 was found to be expressed on endocrine pituitary cells, and an experimental model of anti-CTLA-4-induced hypophysitis was developed in mice (Iwama et al. 2014). In humans, APA were also shown to significantly anticipate the development of pituitary dysfunction (Iwama et al. 2014), and evidence for type II and IV hypersensibility was shown in a unique, postmortem, pathological report of Ipi-induced hypophysitis (Caturegli et al. 2016). The AI phenotype observed in PD1-deficient mice is milder as compared with its CTLA4-deficient counterpart, which is consistent with the milder pituitary phenotype reported with anti-PD1/PDL1 mAbs (Boutros et al. 2016). Thanks to the rapid publication of case reports, followed by single-center series and meta-analysis, the prevalence and evolution of ICPI-H in humans are being increasingly understood, and recommendations by scientific societies and committees are emerging in order to properly face this new complication in cancer patients (Castinetti et al. 2019; Girotra et al. 2018).

The mean prevalence of ICPI-H in patients receiving Ipi was estimated at $9.1 \%$ on series reported up to 2015 (Byun et al. 2017). However, with an increased attention to this complication, ICPI-H was recognized in up to $11-17 \%$ of Ipi-treated

Table 2 Immune checkpoint inhibitors (ICPI) and endocrine dysfunction

\begin{tabular}{|c|c|c|}
\hline Drug class & Pituitary AE & Other endocrine AE \\
\hline $\begin{array}{l}\text { CTLA4 blockade } \\
\text { Ipilimumab } \\
\text { Tremelimumab }\end{array}$ & $\begin{array}{l}\text { Hypophysitis }(0,7-18,1 \%) \\
\text { Hypophysitis }(0,4-2,6 \%)\end{array}$ & $\begin{array}{l}\text { Thyroid dysfunction } \\
\text { Hypothyroidism }(1,9-7,8 \%) \\
\text { Hyperthyroidism }(0,8-3,8 \%) \\
\text { primary adrenal insufficiency }{ }^{\text {b }} \text { (rare) }\end{array}$ \\
\hline $\begin{array}{l}\text { PD1 blockade } \\
\text { Nivolumab } \\
\text { Pembrolizumab } \\
\text { Cemiplimab }^{\mathrm{a}}\end{array}$ & $\begin{array}{l}\text { Hypophysitis }(\leq 1 \%) \text { potential } \\
\text { delayed ACTH deficiency }\end{array}$ & $\begin{array}{l}\text { Thyroid dysfunction } \\
\text { Hypothyroidism }(3,9-12,3 \%) \\
\text { Hyperthyroidism }(1,7-5,7 \%) \\
\text { Diabetes type } 1(<1 \%) \\
\text { Primary adrenal insufficiency }{ }^{\text {b }} \text { (rare) }\end{array}$ \\
\hline $\begin{array}{l}\text { PDL1 blockade } \\
\text { Atezolizumab } \\
\text { Durvalumab } \\
\text { Avelumab }\end{array}$ & Hypophysitis $(\leq 1 \%)$ & $\begin{array}{l}\text { Thyroid dysfunction } \\
\text { Hypothyroidism }(1,7-8,4 \%) \\
\text { Hyperthyroidism }(0,2-1,8 \%) \\
\text { Diabetes type } 1(7 \%) \\
\text { Diabetes insipidus }{ }^{\mathrm{c}} \text { (case report) }\end{array}$ \\
\hline
\end{tabular}

CTLA4 cytotoxic T-lymphocyte antigen 4, $P D 1$ programmed death 1, $P D L 1$ programmed death 1 ligand, $A E$ adverse event, $P A I$ primary adrenal insufficiency

${ }^{\mathrm{a}} \mathrm{New}$ compound, no report on pituitary function

${ }^{b}$ Yet, only ipilimumab, pembrolizumab, and nivolumab have been associated with primary adrenal insufficiency

${ }^{\mathrm{c}} \mathrm{A}$ single case report of avelumab-induced DI has been described yet (Zhao et al. 2018) 
melanoma patients (Faje 2016). Middle-aged male patients appear to be more at risk to develop ICPI-H. Moderate pituitary enlargement has been found to precede headache and/or hypopituitarism, which generally develops after 2-3 months of treatment and is mainly characterized by TSH, ACTH, and FSH/LH deficiencies (up to $96.3 \%, 85.7 \%$, and $74.1 \%$, respectively) (Faje 2016). Earlier or delayed presentation may occur (4-16 weeks) (Byun et al. 2017). Hypoprolactinemia rather than hyperprolactinemia has been reported, and visual impairment is uncommon (Faje 2016). Of note, exceptional cases of optic neuropathies have also been reported (Wilson et al. 2016). The inflammatory phase is typically followed by a decrease in pituitary volume in a few weeks, with a potential recovery of TSH and LH/FSH deficiencies, whereas ACTH deficiency persists in more than $80 \%$ of the cases (Faje 2016). The impact of higher Ipi doses (10 vs $3 \mathrm{mg} / \mathrm{kg}$ ) on the prevalence of ICPI-H remains uncertain (Faje 2016; Byun et al. 2017). There is less experience with tremelimumab, another anti-CTLA4 mAb, but the prevalence of ICPI-H appears to be lower than with Ipi and may not exceed $2.6 \%$, possibly due to a reduced capacity to activate the classical complement pathway (Girotra et al. 2018). ICPI-H during treatment with anti-PD1/anti-PD1L mAbs seems even less frequent $(<1 \%)$ (Barroso-Souza et al. 2018; Girotra et al. 2018); however, attention should be paid to the increasing number of cases presenting with isolated ACTH deficiency during treatment with nivolumab (Ohara et al. 2018). Of note, in these patients symptoms of ACTH deficiency are often delayed (3-5 months up to 9 months). Combined treatment with anti-CTLA-4 and anti-PD1/PD1L mAbs or co-treatment with ICPI and chemotherapy or other target therapies are also being proposed, and an increased risk of ICPI-H has been reported on combined treatment with Ipi and nivolumab (Barroso-Souza et al. 2018). Due to their limited availability and reliability, searching for circulating APA has currently no role in the diagnosis of ICPI-H, which relies essentially on the timing of pituitary symptoms and dysfunction on ICPI treatment and on pituitary MRI, which will reveal in most cases some degree of pituitary enlargement.

The treatment of ICPI-H depends on the severity of ICPI-H, but most patients can be managed with appropriate hydrocortisone and thyroxine replacement therapy, leading to a rapid clinical improvement. Educating non-endocrinologists and patients to the diagnosis, prevention, and treatment of acute adrenal insufficiency is of special importance, because ACTH deficiency is rarely reversible and additional morbid conditions and/or gastrointestinal symptoms are frequent in these patients. Replacement therapy with gonadal steroids should be evaluated case by case, and GH replacement is not indicated in oncological patients. No surgical indications have been reported yet, explaining the absence of pathological descriptions on surgical biopsies. Criteria for treatment with high-dose CG and/or for ICPI withdrawal have been debated. Because high-dose GC have not proven to improve or preserve pituitary function, and might counteract the efficacy of immunotherapy, this option is currently reserved to the most symptomatic patients (e.g., acute illness, severe headache, hyponatremia) (Castinetti et al. 2019; Girotra et al. 2018). In these patients, temporary withdrawal of ICPI may also be proposed upon multidisciplinary evaluation, but the treatment may be restarted after the acute phase. 
An important implication of current experience with ICPI-H is to encourage early recognition of hypopituitarism through systematic endocrine assessment, which is now recommended at baseline, monthly during the first 6 months and then every 2-3 months until the 12th month, and thereafter less frequently or based on patient's symptoms (Castinetti et al. 2019; Girotra et al. 2018). Minimal evaluation should consist of TSH, FT4 and early morning cortisol measurement, and ACTH in the presence of low cortisol (Castinetti et al. 2019; Girotra et al. 2018). Additional evaluation of natremia and gonadal function may also be proposed systematically (Castinetti et al. 2019), and glycemia evaluation should be performed where antiPD1/PDL1-L mAbs are used. Importantly, MRI is recommended in all patients presenting symptoms of ICPI-H and should be repeated in order to recognize a growing mass suggestive of metastasis, which may then represent an indication to a neurosurgical biopsy. Of note, increased pituitary uptake of FDG may be observed in both cases. Systematic search for ICPI-induced AI endocrinopathies, including ICPI-H, is currently being introduced in clinical trials in order to better evaluate their prevalence and clinical implications.

\section{Part IV: Infections and the Pituitary}

Hypophysitis due to infectious agents are relatively rare in developed countries. However, an increasing incidence may be expected because of the rising prevalence of predisposing factors such as immunosuppressive therapies, HIV infection, organ transplantation, or diabetes mellitus and migrations from tropical and developing countries. Pituitary infections may develop in a normal gland (primary infection) or on a preexisting lesion of the sellar region (secondary infection, e.g., complicating the evolution of a RCC, or after pituitary surgery) and may be isolated or part of a disseminated infection, including those involving the central nervous system (CNS). Infectious agents may be bacteria (including a variety of Gram-positive or Gramnegative bacteria and anaerobic bacteria and bacteria in specific infections such as mycobacteria), viruses, fungi, and parasites, which may reach the pituitary through different routes: hematogenous spread; contamination from neighboring anatomical structures - paranasal sinus, sometimes as a result of a cerebrospinal fluid leak, cavernous sinus, meninges, and the brain; and rarely iatrogenic inoculation during pituitary surgery (Guaraldi et al. 2018; Pekic et al. 2018) (Table 3). Pituitary infections may affect patients at any age and induce pseudotumoral symptoms and mass effects, hypopituitarism may be a consequence of pituitary inflammation or destruction by the infective process, DI is frequent, and the prognostic is quite variable, with potential endocrine sequelae, recurrences, and rarely a fatal evolution.

\section{Bacterial Infections and Abscesses}

The clinical presentation of pituitary infections at onset may be more or less suggestive. If headache is generally present (70-90\%), a subacute onset with fever 
Table 3 Causes of pituitary infection

\begin{tabular}{|c|c|c|c|}
\hline Microorganism & Characteristic features & Abscess & Meningitis \\
\hline \multicolumn{4}{|l|}{ Bacteria } \\
\hline Mycobacterium tuberculosis & $\begin{array}{l}\text { Immunocompromised } \\
\text { patients }\end{array}$ & $\mathrm{X}$ & $\mathrm{X}$ \\
\hline Nontuberculous & & $X$ & $\mathrm{X}$ \\
\hline $\begin{array}{l}\text { Mycobacteria (M. gordonae, } M \text {. } \\
\text { malmoense, } M \text {. fortuitum, and } M \text {. } \\
\text { tokaiense) }\end{array}$ & & $\mathrm{X}$ & $\mathrm{X}$ \\
\hline Treponema pallidum & $\begin{array}{l}\text { Immunocompromised } \\
\text { patients }\end{array}$ & & \\
\hline \multicolumn{4}{|l|}{ Other } \\
\hline \multicolumn{4}{|l|}{ Bacterium pyocyaneum } \\
\hline \multicolumn{4}{|l|}{ Brucella } \\
\hline \multicolumn{4}{|l|}{ Citrobacter spp. } \\
\hline \multicolumn{4}{|l|}{ Clostridium difficile } \\
\hline \multicolumn{4}{|l|}{ Corynebacterium } \\
\hline \multicolumn{4}{|l|}{ Escherichia Coli } \\
\hline \multicolumn{4}{|l|}{ Haemophilus influenzae } \\
\hline \multicolumn{4}{|l|}{ Micrococcus } \\
\hline \multicolumn{4}{|l|}{ Neisseria spp. } \\
\hline Salmonella enteritidis & Neonatal sepsis & & \\
\hline \multicolumn{4}{|l|}{ Staphylococcus spp. } \\
\hline \multicolumn{4}{|l|}{ Streptococcus spp. } \\
\hline Virus & & & $\mathrm{X}$ \\
\hline Puumala virus & $\begin{array}{l}\text { Hypophysitis and/or } \\
\text { pituitary hemorrhage }\end{array}$ & & \\
\hline (Zika Virus) & $\begin{array}{l}\text { Autoptic findings/ } \\
\text { experimental mice } \\
\text { model }\end{array}$ & & \\
\hline Coronavirus & $\begin{array}{l}\text { Reversible } \\
\text { hypophysitis in SARS }\end{array}$ & & \\
\hline Cytomegalovirus & $\begin{array}{l}\text { Immunocompromised } \\
\text { patients }\end{array}$ & & \\
\hline Fungi & $\begin{array}{l}\text { Immunocompromised } \\
\text { patients }\end{array}$ & $X$ & $\mathrm{X}$ \\
\hline \multicolumn{4}{|l|}{ Aspergillus } \\
\hline \multicolumn{4}{|l|}{ Nocardia } \\
\hline \multicolumn{4}{|l|}{ Candida } \\
\hline \multicolumn{4}{|l|}{ Pneumocystis jiroveci } \\
\hline \multicolumn{4}{|l|}{ Histoplasma } \\
\hline \multicolumn{4}{|l|}{ Parasites } \\
\hline Toxoplasma gondii & $\begin{array}{l}\text { Immunocompromised } \\
\text { patients }\end{array}$ & $X$ & $\mathrm{X}$ \\
\hline
\end{tabular}


and meningism is reported in $25 \%$ or less. Additional pseudotumoral symptoms include visual field defects, oculomotor palsy, and HP dysfunction - DI, hypopituitarism, and rarely hyperprolactinemia. In the largest series of pituitary abscesses reported in China (33 patients), DI was present in $69.7 \%$ of the cases, panhypopituitarism (including hypoprolactinemia) was present in $75.6 \%$, fever was present in only $18.1 \%$, headache was frequent $(69.7 \%$ ) but usually mild and aspecific, visual disturbances were present in $30.3 \%$ of the cases, and the time between the onset of symptoms and diagnosis ranged from 7 days to 36 months (median 6 months) (Liu et al. 2011). In a previous series from the USA (24 patients), subacute presentations were more frequent, and the prevalence of panhypopituitarism was lower (54.2\%), but a correct diagnosis of pituitary abscess was made only in $20.8 \%$ of the cases before surgery (Vates et al. 2001). These studies underline the frequent diagnostic difficulty of pituitary abscesses at presentation, suggesting that despite their rarity, they should be considered in the differential diagnosis of a non-secreting pituitary mass, especially in the presence of headache, DI, and hypopituitarism. Of note, a suggestive predisposing context was often lacking.

HP dysfunction may also occur in the setting of infectious meningitis of different origin and is likely to be underestimated in clinical practice. Indeed, if hypopituitarism may be difficult to appreciate in critically ill patients (e.g., due to euthyroid sick syndrome, functional hypogonadism, etc.), small prospective studies have clearly shown that a significant proportion of patients develop long-term neuroendocrine sequelae, in particular ACTH and GH deficiency, alone or in combination (Tanriverdi et al. 2012; Tsiakalos et al. 2010). Interestingly, pituitary autoimmunity may be involved in delayed hypopituitarism, which can be best appreciated 12 months after the acute phase (Tanriverdi et al. 2012). Prospective studies on a larger number of patients would be of great interest and may help recognizing risk factors for long-term hypopituitarism and the opportunity of endocrine follow-up after acute meningitis.

The diagnosis of acute or subacute pituitary infection relies on the clinical context and neuroradiological and biological parameters. Unless a preexisting pituitary lesion is already present, pituitary MRI may show an enlarged gland with an intense gadolinium enhancement and thickening of the pituitary stalk, similar to primary hypophysitis or a nonspecific pituitary mass. Pituitary abscesses typically present as cystic or partially cystic sellar/suprasellar masses, frequently with T2 hyperintensity and a suggestive thick peripheral ring enhancement (Liu et al. 2011); bone erosion/ destruction may also be present (Vates et al. 2001). PET imaging may reveal increased ${ }^{18} \mathrm{FDG}$ uptake due to the high metabolic activity of the inflammatory infiltrate, but is not performed routinely. Most importantly, suggestive elevated white blood cell count and inflammatory markers are frequently lacking (Liu et al. 2011; Vates et al. 2001). Hemocultures and/or CSF analysis can be helpful in a septic context, but the identification of causative organism is often disappointing (Guaraldi et al. 2018). The final diagnosis of a pituitary abscess will therefore usually be made at surgery, revealing the presence of a cremous pus, and bacteriological analysis may disclose the causative agents in a variable proportion of cases - from less than $20-46 \%$ of the cases (Liu et al. 2011; Vates et al. 2001). Gram-positive bacteria are 
the most frequently isolated (Table 3). The treatment of pituitary abscesses is based on surgical drainage of the pus and prolonged systemic antibiotherapy, which is best managed by a specialist in infectious diseases. Postoperative remission of headache is generally observed, whereas the rate of pituitary function recovery is highly variable (Liu et al. 2011; Vates et al. 2001). Subsequent regression may lead to a condition of secondary empty sella.

\section{Specific Bacterial Infections}

Pituitary infection by Mycobacterium tuberculosis is the best characterized. Although primary tubercular (TBC) abscess of the pituitary is very rare, infections of the CNS occur in 2-5\% of TBC patients - up to $10 \%$ of those with an HIV-related disease. Brain MRI may reveal abnormalities of the HP region in about $10 \%$ of patients with TBC meningitis (tuberculoma, thickening of pituitary stalk, and meningeal enhancement), but hormonal abnormalities may occur even in the absence of radiologic involvement (Dhanwal et al. 2010). Visual impairment may occur as a result of a sellar/extrasellar tuberculoma or an optochiasmatic arachnoiditis. In the largest available prospective study from India, HP dysfunction was observed in 62 out of 115 patients affected by TBC meningitis (53.9\%), with single and multiple axes dysfunction in $30.4 \%$ and $23.5 \%$ of the cases, respectively (More et al. 2017). Hypogonadism was the most frequent $(33.9 \%)$, possibly associated with hyperprolactinemia (22.6\%), followed by TSH and ACTH deficiency (17.4\% each). Similar results were reported in a previous series of 75 patients, with a higher prevalence of TSH and ACTH deficiency $(30.7 \%$ and $42.7 \%$ of the cases, respectively) (Dhanwal et al. 2010). Remarkably, none had DI (Dhanwal et al. 2010; More et al. 2017), but nearly $10 \%$ of the patients had a syndrome of inappropriate antidiuretic hormone secretion (SIADH) (More et al. 2017). Of note, hypopituitarism may be recognized as a long-term sequela, up to several years after TBC meningitis. Surgery may be indicated for a sellar TBC abscess, and the histopathological analysis will typically reveal caseating granulomas with giant cells. Staining for acid fast bacilli may be positive, but the diagnosis is more readily confirmed by mycobacterial DNA detection on the surgical biopsy. Antituberculous drugs are generally effective, but surgery may be indicated for resistant TBC hypophysitis or tuberculomas (Pekic et al. 2018).

Spirochete Treponema pallidum may also cause HP dysfunction with Gr-H and syphilitic gumma in the sellar region, and congenital forms have been described. The incidence of syphilis is rising in HIV-infected patients, with a higher risk of neurological complications. Sellar and suprasellar localizations cause severe headache and hypopituitarism. MRI shows a pituitary gland enlargement, and the diagnosis is confirmed by positive treponemal antibody or by the detection of treponema on the resected pituitary in the case of surgery. Early diagnosis and treatment with penicillin may avoid neurosurgery (Bricaire et al. 2015). 


\section{Viral Infections}

Several viruses can cause CNS infection and consequent HP dysfunction, although this is still poorly considered in clinical practice. Common acute viral meningitis may induce neuroendocrine dysfunction and sequela as do bacterial meningitis (Tanriverdi et al. 2012; Tsiakalos et al. 2010), and there are reports of DI occurring after common viral infections (including cytomegalovirus, herpes simplex, varicella zoster, etc.), mainly in immunocompromised patients (Pekic et al. 2018). Reversible hypophysitis with ACTH insufficiency has also been reported in $39.3 \%$ of 61 survivors from severe acute respiratory syndrome (SARS) caused by Coronavirus (Leow et al. 2005). Infections by Puumala hantavirus (PUUV), which are endemic zoonoses in some countries of Europe (especially in Northern Europe) and cause nephropathia epidemica (hemorrhagic fever with renal syndrome), may in some cases directly involve the pituitary gland. This may induce acute symptomatic hypophysitis and/or hemorrhage requiring hormone replacement therapy, but longterm sequela appears to be rare (Partanen et al. 2016). Pituitary dysfunction, mainly central hypogonadism and rarely corticotroph insufficiency, has been reported in HIV patients (Mirza et al. 2018). Infections by Zika virus, a member of flaviviruses transmitted by mosquito bites, endemic in Northern Brazil and in other tropical countries, may cause several neurological disorders, in particular microcephaly and calcifications in newborns from infected mothers. Experimental data in mice have revealed GH deficiency and central hypothyroidism due to hypothalamic - not pituitary - infection and inflammation, and GH treatment was able to improve somatic growth in affected animals (Wu et al. 2018). As multifactorial growth delay has been reported in Zika-infected newborns and children, this would deserve further investigations in humans.

\section{Fungal and Parasitic Infections}

There are occasional case reports of pituitary abscesses caused by Aspergillus, Nocardia, Candida, or Pneumocystis jiroveci, usually in immunocompromised patients. Their clinical presentation is similar to other pituitary abscesses, and the definitive diagnosis requires histopathological examination and identification of fungus DNA. Treatment is based on association of abscess drainage and antifungal therapy (Pekic et al. 2018). Similarly, Toxoplasma gondii, which is the most common parasite infecting humans, may induce severe complications in immunocompromised patients and in its congenital form. In such cases, CNS involvement is common and may cause HP dysfunction. Of note, brain lesions may mimic intracranial metastases on MRI, and the diagnosis is confirmed by identification of parasite on brain biopsy. Antimicrobial therapy is generally effective (Pekic et al. 2018). 


\section{Conclusion}

The HP unit may be involved in a variety of systemic conditions. LYH may be primary, isolated, or associated with other endocrine or non-endocrine AI diseases. The same may occur in ICPI-H, which has emerged as a relatively frequent entity, with prevalence and clinical presentation depending on the causative drug(s). While ICPI-H is being increasingly recognized by oncologists, other causes of HP dysfunction in oncological patients should not be underestimated. Gr-H may be primary or secondary to preexisting pituitary lesions but may also be part of systemic infectious and noninfectious granulomatosis. Particular attention should be paid to distinguish between $\mathrm{Gr}-\mathrm{H}$ and histiocytic disorders, which are now recognized as neoplastic diseases and should be managed by hematologists. IgG4R-H remains a rare but probably underestimated condition and in most cases is part of a systemic IgG4R-D. The spectrum of pituitary infections and HP sequelae of meningitis is also enlarging. Overall, the description of new causes of hypophysitis has modified not only their epidemiology but also their diagnostic and clinical approach. Although pathological examination remains the gold standard for the diagnostic of inflammatory, granulomatous, and histiocytic HP disorders, the need for a diagnostic neurosurgical biopsy has decreased in particular conditions, e.g., ICPI-H or systemic diseases, which may be reliably recognized on the basis of their clinical setting and/or extrapituitary investigations. On the other hand, a surgical approach may be necessary in the presence of a nonfunctioning pituitary mass of uncertain origin, in order to ensure the diagnosis and/or relieve mass symptoms or to drain septic abscesses. The optimal diagnostic and management of ICPI-H and systemic and infective diseases relies on increased awareness of these heterogenous conditions by pituitary and non-pituitary specialists, including neuroradiologists and pathologists. Multidisciplinary collaboration is essential to ensure proper management of HP manifestations, including the treatment of endocrine dysfunction and mass effects, where present, and of the underlying condition.

\section{Cross-References}

Autoimmune Polyendocrine Syndromes (APS) or Multiple Auto-immune Syndromes (MAS): An Overview

\section{References}

Allen CE, Merad M, McClain KL. Langerhans-cell Histiocytosis. N Engl J Med. 2018;379 (9):856-68.

Bando H, Iguchi G, Okimura Y, Odake Y, Yoshida K, Matsumoto R et al. A novel thymomaassociated autoimmune disease: anti-PIT-1 antibody syndrome. Sci Rep. 2017;7:43060. Available from: https://doi.org/10.1038/srep43060 
Barroso-Sousa R, Barry WT, Garrido-Castro AC, Hodi FS, Min L, Krop IE, et al. Incidence of endocrine dysfunction following the use of different immune checkpoint inhibitor regimens: a systematic review and meta-analysis. JAMA Oncol. 2018;4(2):173-82.

Bellastella G, Rotondi M, Pane E, Dello Iacovo A, Pirali B, Dalla Mora L, et al. Italian autoimmune Hypophysitis network study. Predictive role of the immunostaining pattern of immunofluorescence and the titers of antipituitary antibodies at presentation for the occurrence of autoimmune hypopituitarism in patients with autoimmune polyendocrine syndromes over a five-year followup. J Clin Endocrinol Metab. 2010;95(8):3750-7.

Bensing S, Fetissov SO, Mulder J, Perheentupa J, Gustafsson J, Husebye ES, et al. Pituitary autoantibodies in autoimmune polyendocrine syndrome type 1. Proc Natl Acad Sci U S A. 2007;104(3):949-54.

Bernreuther C, Illies C, Flitsch J, Buchfelder M, Buslei R, Glatzel M, et al. IgG4-related hypophysitis is highly prevalent among cases of histologically confirmed hypophysitis. Brain Pathol. 2017;27(6):839-45.

Berti A, Cavalli G, Guglielmi B, Biavasco R, Campochiaro C, Tomelleri A, Nicoletti R, Panzacchi A, Ferrarini M, Dagna L. Tocilizumab in patients with multisystem Erdheim-Chester disease. Oncoimmunology. 2017;6(6):e1318237. Available from: https://doi.org/10.1080/ 2162402X.2017.1318237.

Betterle C, Presotto F. Autoimmune Polyendocrine syndrome (APS) or multiple autoimmune syndrome (MAS). In: Walker S, Jara L, editors. Handbook of systemic auto-immune diseases, endocrine manifestations of systemic autoimmune diseases. Amsterdam: Elsevier; 2008. p. $135-48$.

Bianchi A, Mormando M, Doglietto F, Tartaglione L, Piacentini S, Lauriola L, et al. Hypothalamitis: a diagnostic and therapeutic challenge. Pituitary. 2014;17(3):197-202.

Boutros C, Tarhini A, Routier E, Lambotte O, Ladurie FL, Carbonnel F, et al. Safety profiles of antiCTLA-4 and anti-PD-1 antibodies alone and in combination. Nat Rev Clin Oncol. 2016;13 (8):473-86.

Bricaire L, Van Haecke C, Laurent-Roussel S, Jrad G, Pertherat J, Gaillard S, et al. The great imitator in endocrinology: a painful Hypophysitis mimicking a pituitary tumor. J Clin Endocrinol Metab. 2015;100(8):2837-40.

Brito-Zeron P, Kostov B, Bosch X, Acar-Denizli N, Ramos-Casals M, Stone JH. Therapeutic approach to IgG4-related disease: a systematic review. Medicine (Baltimore). 2016;95(26): e4002. Available from: https://doi.org/10.1097/MD.0000000000004002.

Byun DJ, Wolchok JD, Rosenberg LM, Girotra M. Cancer immunotherapy - immune checkpoint blockade and associated endocrinopathies. Nat Rev Endocrinol. 2017;13(4):195-207.

Campochiaro C, Tomelleri A, Cavalli G, Berti A, Dagna L. Erdheim-Chester disease. Eur J Intern Med. 2015;26(4):223-9.

Carpinteri R, Patelli I, Casanueva FF, Giustina A. Pituitary tumours: inflammatory and granulomatous expansive lesions of the pituitary. Best Pract Res Clin Endocrinol Metab. 2009;23 (5):639-50.

Castinetti F, Albarel F, Archambeaud F, Bertherat J, Bouillet B, Buffier P, et al. French Endocrine Society guidance on endocrine side-effects of immunotherapy. Endocr Relat Cancer. 2019;26 (2):G1-G18.

Castle-Kirszbaum M, Goldschlager T, Ho B, Wang YY, King J. Twelve cases of pituitary metastasis: a case series and review of the literature. Pituitary. 2018;21(5):463-73.

Caturegli P, Newschaffer C, Olivi A, Pomper MG, Burger PC, Rose NR. Autoimmune hypophysitis. Endocr Rev. 2005;26(5):599-614.

Caturegli P, Di Dalmazi G, Lombardi M, Grosso F, Larman HB, Larman T, et al. Hypophysitis secondary to cytotoxic T-lymphocyte-associated protein 4 blockade: insights into pathogenesis from an autopsy series. Am J Pathol. 2016;186(12):3225-35.

Cives M, Simone V, Rizzo FM, Dicuonzo F, Cristallo Lacalamita M, Ingravallo G, et al. ErdheimChester disease: a systematic review. Crit Rev Oncol Hematol. 2015;95(1):1-11. 
Courtillot C, Laugier Robiolle S, Cohen Aubart F, Leban M, Renard-Penna R. Drier et al. endocrine manifestations in a monocentric cohort of 64 patients with Erdheim-Chester disease. J Clin Endocrinol Metab. 2016;101(1):305-13.

Crowne E, Gleeson H, Benghiat H, Sanghera P, Toogood A. Effect of cancer treatment on hypothalamic-pituitary function. Lancet Diabetes Endocrinol. 2015;3(7):568-76.

Dhanwal KD, Vyas A, Sharma A, Saxena A. Hypothalamic pituitary abnormalities in tubercular meningitis at the time of diagnosis. Pituitary. 2010;13(4):304-10.

Donadieu J, Rolon MA, Thomas C, Brugieres L, Plantaz D, Emile JF, et al. Endocrine involvement in pediatric-onset Langerhans' cell histiocytosis: a population-based study. J Pediatr. 2004a;144 (3):344-50.

Donadieu J, Rolon MA, Pion I, Thomas C, Doz F, Barkaoui M, et al. Incidence of growth hormone deficiency in pediatric-onset Langerhans cell histiocytosis: efficacy and safety of growth hormone treatment. J Clin Endocrinol Metab. 2004b;89(2):604-9.

Emens LA, Ascierto PA, Darcy PK, Demaria S, Eggermont AMM, Redmond WL, et al. Cancer immunotherapy: opportunities and challenges in the rapidly evolving clinical landscape. Eur J Cancer. 2017;81:116-29.

Fahrner B, Prosch H, Minkov M, Krischmann M, Gadner H, Prayer D, et al. Long-term outcome of hypothalamic pituitary tumors in Langerhans cell histiocytosis. Pediatr Blood Cancer. 2012;58 (4):606-10.

Faje A. Immunotherapy and hypophysitis: clinical presentation, treatment, and biologic insights. Pituitary. 2016;19(1):82-92.

Ferguson SD, Waguespack SG, Langford LA, Ater JL, McCutcheon IE. Fatal juvenile xanthogranuloma presenting as a sellar lesion: case report and literature review. Childs Nerv Syst. 2015;31(5):777-84.

Girotra M, Hansen A, Farooki A, Byun DJ, Min L, Creelan BC et al. The current understanding of the endocrine effects from immune checkpoint inhibitors and recommendations for management. JNCI Cancer Spectr. 2018;2(3):pky021. Available from: https://doi.org/10.1093/jncics/ pky021.

Girschikofsky M, Arico M, Castillo D, Chu A, Doberauer C, Fichter J, et al. Management of adult patients with Langerhans cell histiocytosis: recommendations from an expert panel on behalf of Euro-Histio-Net. Orphanet J Rare Dis. 2013;8:72. Available from: http://www.ojrd.com/con tent $/ 8 / 1 / 72$.

Grugni G, Crino A, De Bellis A, Convertino A, Bocchini S, Maestrini S, et al. Auto-immune pituitary involvement in Prader-Willi syndrome: new perspective for further research. Endocrine. 2018;62(3):733-6.

Guaraldi F, Giordano R, Grottoli S, Ghizzoni L, Arvat E, Ghigo E. Pituitary autoimmunity. Front Horm Res. 2017;48:48-68.

Guaraldi F, Casar-Borota O, Jaffrain-Rea ML. Hypophysitis. In: Huhtaniemi I, Martini L, editors. Encyclopedia of endocrine diseases. 2nd ed. Amsterdam: Elsevier; 2018. p. 325-338. Available from: https://doi.org/10.1016/B978-0-12-801238-3.64944-9.

Héritier S, Barkaoui MA, Miron J, Thomas C, Moshous D, Lambilliotte A, et al. Incidence and risk factors for clinical neurodegenerative Langerhans cell histiocytosis: a longitudinal cohort study. Br J Haematol. 2018;183(4):608-17.

Honegger J, Schlaffer S, Menzel C, Droste M, Werner S, Elbelt U, et al. Diagnosis of primary hypophysitis in Germany. J Clin Endocrinol Metabol. 2015;100(10):3841-9.

Hunn BH, Martin WG, Simpson S Jr, Mclean CA. Idiopathic granulomatous hypophysitis: a systematic review of 82 cases in the literature. Pituitary. 2014;17(4):357-65.

Husebye ES, Anderson MS, Kämpe O. Autoimmune Polyendocrine Syndromes. N Engl J Med. 2018;378(12):1132-41.

Iwama S, De Remigis A, Callahan MK, Callahan MK, Slovin SF, Wolchok JD, et al. Pituitary expression of CTLA-4 mediates hypophysitis secondary to administration of CTLA-4 blocking antibody. Sci Transl Med. 2014;6(230):230ra45. Available from: https://doi.org/10.1126/ scitranslmed.3008002. 
Iwata N, Iwama S, Sugimura Y, Yasuda Y, Nakashima K, Takeuchi S, et al. Anti-pituitary antibodies against corticotrophs in IgG4-related hypophysitis. Pituitary. 2017;20(3):301-10.

Kahaly GJ. Polyglandular autoimmune syndromes. Eur J Endocrinol. 2009;161(1):11-20.

Kalra AA, Riel-Romero RM, Gonzalez-Toledo E. Lymphocytic hypophysitis in children: a novel presentation and literature review. J Child Neurol. 2011;26(1):87-94.

Kaltsas GA, Powles TB, Evanson J, Plowman PN, Drinkwater JE, Jenkins PJ, et al. Hypothalamopituitary abnormalities in adult patients with langerhans cell histiocytosis: clinical, endocrinological, and radiological features and response to treatment. J Clin Endocrinol Metab. 2000;85 (4):1370-6.

Kamisawa T, Zen Y, Pillai S, Stone JH. IgG4-related disease. Lancet. 2015;385(9976):1460-71.

Karim F, Loeffen J, Bramer W, Westenberg L, Verdijk R, van Hagen M, van Laar J. IgG4-related disease: a systematic review of this unrecognized disease in pediatrics. Pediatr Rheumatol Online J. 2016;14(1):18. Available from: https://doi.org/10.1186/s12969-016-0079-3.

Khosroshahi A, Wallace ZS, Crowe JL, Akamizu T, Azumi A, Carruthers MN, et al. International consensus guidance statement on the management and treatment of IgG4-related. Arthritis Rheumatol. 2015;67(7):1688-99.

Kleinschmidt-DeMasters BK, Lillehei KO, Hankinson TC. Review of xanthomatous lesions of the sella. Brain Pathol. 2017;27(3):377-95.

Kyriacou A, Gnanalingham K, Kearney T. Lymphocytic hypophysitis: modern day management with limited role for surgery. Pituitary. 2017;20(2):241-50.

Lee S, Choi JH, Kim CJ, Kim JH. Clinical interrogation for unveiling an isolated Hypophysitis mimicking pituitary adenoma. World Neurosurg. 2017;99:735-44.

Leow MK, Kwek DS, Ng AW, Ong KC, Kaw GJ, Lee LS. Hypocortisolism in survivors of severe acute respiratory syndrome (SARS). Clin Endocrinol. 2005;63(2):197-202.

Leporati P, Landek-Salgado MA, Lupi I, Chiovato L, Caturegli P. IgG4-related hypophysitis: a new addition to the hypophysitis spectrum. J Clin Endocrinol Metab. 2011;96(7):1971-80.

Liu F, Li G, Yao Y, Yang Y, Ma W, Li Y, Chen G, Wang R. Diagnosis and management of pituitary abscess: experiences from 33 cases. Clin Endocrinol. 2011;74(1):79-88.

Liu Y, Wang L, Zhang W, Pan H, Yang H, Deng K et al. Hypophyseal involvement in immunoglobulin G4-related disease: a retrospective study from a single tertiary center. Int J Endocrinol. 2018;2018:7637435. Available from: https://doi.org/10.1155/2018/7637435.

Lupi I, Manetti L, Raffaelli V, Lombardi M, Cosottini M, Iannelli A, et al. Diagnosis and treatment of autoimmune hypophysitis: a short review. J Endocrinol Investig. 2011;134:e245-52.

Martin-Grace J, Murialdo G, Tamagno G. Hypothalamic-pituitary alterations in patients with Neurosarcoidosis. EMJ Neurol. 2015;3(1):51-6.

Mirza FS, Luthra P, Chirch L. Endocrinological aspects of HIV infection. J Endocrinol Investig. 2018;41(8):881-99.

Monsereenusorn C, Rodriguez-Galindo C. Clinical characteristics and treatment of Langerhans cell Histiocytosis. Hematol Oncol Clin North Am. 2015;29(5):853-73.

More A, Verma R, Garg RK, Malhotra HS, Sharma PK, Uniyal R, et al. A study of neuroendocrine dysfunction in patients of tuberculous meningitis. J Neurol Sci. 2017;379:198-206.

Ohara N, Ohashi K, Fujisaki T, Oda C, Ikeda Y, Yoneoka Y, et al. Isolated Adrenocorticotropin deficiency due to Nivolumab-induced Hypophysitis in a patient with advanced lung adenocarcinoma: a case report and literature review. Intern Med. 2018;57(4):527-35.

Partanen T, Koivikko M, Leisti P, Salmela P, Pääkkö E, Kurttunene A, et al. Long-term hormonal follow-up after human Puumala hantavirus infection. Clin Endocrinol. 2016;84(1):85-91.

Pekic S, Miljic D, Popovic V. Infections of the hypothalamic-pituitary region. In: Feingold KR, Anawalt B, Boyce A, et al., editors. Endotext [Internet]. South Dartmouth: MDText.com, Inc.; 2018. Available from: https://www.ncbi.nlm.nih.gov/books/NBK532083/.

Pileri SA, Jaffe R, Facchetti F, Jones DM, Jaffe ES. Histiocytic and dendritic cell neoplasms. Introduction. In: Swerdlow SH, Campo E, Harris NL, Jaffe EJ, Pileri SA, Stein H, Thiele J, editors. World Health Organization (WHO) Classification of Tumours of Haematopoietic and 
Lymphoid Tissues. Revised 4th ed. Lyon: International Agency for Research on Cancer (IARC); 2017. p. 466-8.

Porter N, Beynon HL, Randeva HS. Endocrine and reproductive manifestations of sarcoidosis. Q J Med. 2003;96:553-61.

Rotondo F, Munoz DG, Hegele RG, Gray B, Khatun N, Bonert M, Kovacs K. Rosai-Dorfman disease involving the neurohypophysis. Pituitary. 2010;13(3):256-9.

Shikuma J, Kan K, Ito R, Hara K, Sakai H, Miwa T, et al. Critical review of IgG4-related hypophysitis. Pituitary. 2017;20(2):282-91.

Stone JH, Zen Y, Deshpande V. IgG4-related disease. N Engl J Med. 2012;366(6):539-51.

Tanriverdi F, De Bellis A, Teksahin H, Alp E, Bizzarro A, Sinisi AA, et al. Prospective investigation of pituitary functions in patients with acute infectious meningitis: is acute meningitis induced pituitary dysfunction associated with autoimmunity? Pituitary. 2012;15(4):579-88.

Tao T, Zhang Z, Li H. Lymphocytic hypophysitis associated with Behcet's disease: a case report and review of the literature. Neuro Endocrinol Lett. 2018;39(1):43-8.

Tsiakalos A, Xynos ID, Sipsas NV, Kaltsas G. Pituitary insufficiency after infectious meningitis: a prospective study. J Clin Endocrinol Metab. 2010;95(7):3277-81.

Vates GE, Berger MS, Wilson CB. Diagnosis and management of pituitary abscess: a review of twenty-four cases. J Neurosurg. 2001;95(2):233-41.

Weindorf SC, Frederiksen JK. IgG4-related disease: a reminder for practicing pathologists. Arch Pathol Lab Med. 2017;141(11):1476-83.

Weiss LM, Jaffe R, Facchetti F. Tumours derived from Langerhans cells. In: Swerdlow SH, Campo E, Harris NL, Jaffe EJ, Pileri SA, Stein H, Thiele J, editors. World Health Organization (WHO) Classification of Tumours of Haematopoietic and Lymphoid Tissue. 4th ed. Lyon: International Agency for Research on Cancer (IARC); 2017. p. 470-2.

Wilson MA, Guld K, Galetta S, Walsh RD, Kharlip J, Tamhankar M et al. Acute visual loss after ipilimumab treatment for metastatic melanoma . J Immunother Cancer. 2016;4:66. Available from: https://doi.org/10.1186/s40425-016-0170-9.

Wu YH, Cui XY, Yang W, Fan DY, Liu D, Wang PG, et al. Zika virus infection in hypothalamus causes hormone deficiencies and leads to irreversible growth delay. Cell Rep. 2018;25 (6):1537-47.

Zatelli MC, Ambrosio MR, Bondanelli M, Degli UE. Pituitary side effects of old and new drugs. J Endocrinol Investig. 2014;37(10):917-23.

Zhao C, Tella SH, Del Rivero J, Kommalapati A, Ebenuwa I, Gulley J, et al. Anti-PD-L1 treatment induced central diabetes insipidus. J Clin Endocrinol Metab. 2018;103(2):365-9.

Zinn DJ, Chakraborty R, Allen CE. Langerhans cell Histiocytosis: emerging insights and clinical implications. Oncology (Williston Park). 2016;30(2):122-32. 